Revista Iberoamericana, Vol. LXXI, Núm. 211, Abril-Junio 2005, 403-416

\title{
LA IMAGINACIÓN SALVAJE: MAROSA DI GIORGIO
}

\author{
POR \\ María Rosa Olivera-Williams \\ University of Notre Dame
}

I’m Nobody! Who are you?
Are you -Nobody- too?
..
How dreary -to be- Somebody!
To tell your name -the livelong June--
To an admiring Bog!
Emily Dickinson
Soy la Virgen.
Estoy sola. Silba el viento. ¿Adónde voy? ¿Adónde
voy?
y jamás habrá respuesta.

I. EL LIBRO

Desde 1954, la uruguaya Marosa Di Giorgio (1932) sorprende con una obra que subvierte la división de los géneros literarios, y rehúsa clasificaciones. Sus poemas en prosa cuentan extrañas historias y, sin embargo, debido a que las mismas no se desarrollan en dimensiones temporales, sino espaciales, dando prioridad a imágenes en constante movimiento, subrayan su naturaleza lírica. Por supuesto, se trata de poemas híbridos, ${ }^{1}$ engendro de poesía y prosa para captar el mundo interior y exterior en el momento de atracción de ambos, o de superación de los límites entre lo subjetivo y lo material. Ángel

\footnotetext{
${ }^{1}$ Roberto Echevarren encuentra que la mezcla de géneros, poemas en prosa, poema-ensayo, o prosa cortada, es una de las características más interesantes de "los poetas transplatinos" (Marosa Di Giorgio, Osvaldo Lamborghini y Néstor Perlongher), quienes podrían entrar en la categoría más amplia de representantes de la poesía neobarroca. Echevarren entiende que la poesía neobarroca latinoamericana se presta para articular la búsqueda de verdad en el siglo xx, cuando el "subjetivismo ilusorio" y el "utopismo autoritario" decimonónicos han sido superados. Por lo tanto, las muestras neobarrocas están laxamente relacionadas, siendo quizás el único punto de contacto "una tendencia al concepto singular, no general” y una imperiosa necesidad de superar cualquier límite, ya sea el de las expectativas de los lectores del poema y el lenguaje del mismo, o las experiencias que se despliegan en el espacio del poema (9-20).
} 
Rama se preguntaba si Di Giorgio escribía poemas secretos e inconfesables o relatos fragmentarios contados por las voces de la furia y la libertad. ${ }^{2}$ Por su parte, Wilfredo Penco se cuestionaba si se debería hablar de una larga novela inconclusa, o breves narraciones que nacen de la poesía, para contar una misma historia de maravillas y misterios. Sus doce poemarios hasta el 2000, año en que se publicó la última edición, en dos volúmenes, de Los papeles salvajes constituyen un único libro, una obra indivisible y orgánica que se reitera incansablemente y con nuevos bríos, en un despliegue erótico de múltiples capítulos.

El libro único de Di Giorgio que como un gigantesco árbol crece constantemente, ha echado asimismo brotes en prosa. En 1993 publicó la colección de relatos Misales, en 1997, Camino de las pedrerías, en 1999, la novela Reina Amelia, y en 2003, Rosa mística, nuevos cuentos eróticos. Sin embargo, estas obras en prosa también son muestras de la mezcla de géneros que la caracteriza, ya que no sólo el discurso de estas ficciones es exquisitamente lírico, sino que las imágenes y el punto de vista narrativo reitera la mirada de los enunciantes poéticos de Los papeles salvajes. Así, Amelia, esa “zona semiprohibida” que se convierte en el eterno fluir del mar (Mesa de esmeralda 117), y es probablemente el verdadero nombre de la hablante poética en La liebre de marzo, ${ }^{3}$ o sea que es uno de los centros cambiantes y eternos desde donde Di Giorgio percibe el mundo de Los papeles salvajes, ocupa una posición más sostenida en la novela. Sin embargo, tanto novela poética como poemario en prosa logran por medio de su unicidad y extrañeza la atención necesaria requerida por Joseph Conrad para "hacernos ver". Di Giorgio "nos hace ver" un mundo sorprendente, paradójicamente remoto y cercano, en el cual al asombro del primer choque prosigue la familiaridad de una verdad velada, secreta y conocida. Ella "nos hace ver,” especialmente, la invisibilidad e inaudibilidad de la mujer poeta, ser camaleónico, cuya fuerza va a radicar en sus múltiples máscaras y disfraces.

Si la poesía de Di Giorgio sorprendía por la hibridación de géneros, también lo hace por cultivar un mundo rural, en tiempos en los que la poesía urbana es hegemónica. Los papeles... presenta un mundo agrario, onírico y concreto. Sus personajes, por los cuales se mira el mundo, son animales reales y fantásticos, tanto oriundos de su Salto natal como imaginarios de una Italia contada en historias de familia. ${ }^{4}$ Las mismas características se observan en el mundo vegetal que convive con el animal y el humano. Las flores se vuelven estrellas, los tomates, caras rojas sufrientes y sexuadas, las mariposas, hombres y mujeres.

\footnotetext{
2 Rama, en su ensayo canónico La generación crítica 1939-1969, señala a Marosa Di Giorgio como ejemplo de la renovación y reconversión de la poesía uruguaya de los sesenta al ser hibridizada por otros géneros, como “el cuento, el poema en prosa, o las expresiones más estrictamente líricas”, 189. ${ }^{3}$ En Los papeles salvajes. I: 306. Todas las citas pertenecen a esta edición y aparecerán en el texto con el número del volumen, y el de las páginas.

${ }^{4}$ Teresa Porzecanski explica la hibridación del paisaje salteño por parte del abuelo de Marosa, Eugenio Medici, en los siguientes términos: "With tremendous zeal, Eugenio Medici worked to recreate the orchards of Florence... A businessman whose schemes often lacked substance; he was a dreamer as well as a grower. In the family orchards, the fields full of olive trees, and the nests where the silkworm cocoons took shape, a little girl would grow up, and poetic imagination would transform the way in which the countryside had, until then, been portrayed in Uruguayan literature" (305).
} 
Es un mundo donde se dan cita la familia extensa de Marosa, generalmente fantasmagónica, con hadas, demonios rojos, ángeles negros, y la sempiterna presencia de la Virgen María: “Dónde apareció la Virgen? ... Estaba por todos lados. A la vez, por todos lados. Con el vestido blanco, y capuchón, y en la mano, no sé qué, una fresia o un pollito. Yo quedé harta de esa repetición, reverberación” (I: 307). No hay orden jerárquico entre el mundo vegetal, animal, humano y espiritual. Todo se da en un mismo plano, el del espacio del poema, movido por el deseo de armonía y de continuidad. Así como la Virgen María "estaba por todos lados," demandando que la hablante, testigo y portavoz de ese mundo, se convierta ella misma en Virgen, como en el poema que nos sirve de epígrafe, "Soy la Virgen...” (I: 312), también animales, insectos, plantas, demonios, ángeles, se convierten en “ojos” que logran hacernos ver a nuevo, de manera diferente, todo desde la relación madre-hija, al ritual de la comida, la comunión, las bodas, o a deseos de uniones insólitas, generalmente hermafroditas. ${ }^{5}$ El acto de la lectura ilumina un mundo esencialmente erótico y erotizado, en el que todo se abre, se des-naturaliza, está en movimiento para integrarse a otro ser u objeto que actúa como centro de atracción. La hablante es mujer y lechuza, violada por un lobo, deseada sexualmente por un gato, mariposa y mujer, muñeca de loza, muñeca de mazapán y, también, liebre:

Ser liebre.

Le veo las orejas como hojas, los ojos pardos, los bigotes de pistilo, un tic en la boca oscura, de alhelí....

Se mueve con un rumor de tambor. ¿'Será un jefe liebre? ¿una liebre madre? ¿O un hombre liebre? ¿una mujer liebre? ¿Seré yo misma? Me toco las orejas delicadas, los ojos pardos, el bigote fino, la boca de alhelí, la dentadura anacarada, oscura. (I: 315)

Interesa reiterar que estas transmutaciones no privilegian ninguna de las miradas que integran a un enunciante en eterna metamorfosis. Por lo contrario, las diferentes perspectivas -ya sea la del pájaro, insecto, animal, muñeca, virgen, etc.- son las que permiten que el mundo de Los papeles... se enriquezca con múltiples interpretaciones, ya que quien lo proyecta deviene sus múltiples máscaras. El “yo” enunciante puede ser tanto la propia Marosa Di Giorgio como su imaginación desbordada. Las máscaras, como nos han enseñado la poesía escrita por mujeres, y la crítica feminista (Sylvia Molloy, Gwen Kirkpatrick, Mary Jacobus, Nancy K. Miller, entre otras), se han hecho carne y articulan el complejo cuestionamiento de la identidad de la mujer que escribe.

La falta de jerarquización y divisiones entre lo vegetal, animal, humano, fantástico, metafísico, parecería apuntar en una primera lectura a un estado primigenio e inocente, "allí donde el incesto aún no estaba prohibido, donde los animales se comunicaban con

\footnotetext{
5 "Verdes, color rosa, anilladas, dibujadas. Se dice de ellas que tienen relaciones consigo, y se las ve en el espasmo./.../ Las consideran sólo ensueños, representación de los pecados de los hombres/ Pero yo, de niñita, a la luz del sol y de la luna, creo en ellas, sé que son, de verdad./ Las vi abrir los labios negros como la noche ...enfrentar la propia línea, jugando y peleando y en el amor a solas, retorcerse hasta morir". Asimismo, en el poema al caracol, el molusco terrestre es Hermes y Afrodita, y se desea a sí mismo: "En ese pedacito blanco están Hermes y Afrodita; así se detiene y se conjuga solo" (I: 301).
} 
los hombres y donde el sexo no estaba separado de la totalidad del cuerpo” (Mattoni 5). Parecería el mundo paradisíaco, anterior a la caída, regido por la centralidad armoniosa de Dios: "Dios en el centro, y aunque se moviese todo giraba a su alrededor" (II: 110). Este mundo que insiste en la recreación de los momentos de gestación, huevos puestos por la hablante, huevos de los que ella nace, huevos que son ella, para dar unos pocos ejemplos, estaría captado aparentemente por la mirada de la niña que no es consciente todavía de las prohibiciones sociales. Sin embargo, quien mira no es una niña, sino una mujer adulta que puede ser niña, así como también es insecto, ave, animal y huevo. La hablante hija se convierte en mujer/madre de su madre: “A veces, cuando veo una pequeña niña, me digo: ¿No será Clementina Médici que ha vuelto? / Y siento deseos de robarla y de criarla” (II: 304). El constante desplazamiento del punto de vista de la enunciación hace imposible que se pueda considerar el mundo de chacras, animales, plantas lujuriosas, de los familiares de la Marosa/hablante y personaje (padres, abuelos, tías, primos, vecinos), y de seres mitológicos, como signo de un mundo ajeno a la ley, a los tabúes y el pecado. Por lo contrario, el adjetivo "salvaje” del título no se refiere a una escritura (papeles) desde la posición ingenua/salvaje de los niños, sino desde las múltiples perspectivas que adopta la enunciación para oponerse a la cosificación de un orden positivista.

Las miradas nómadas, constantemente transubstanciadas, no dejan de ver y hacer ver las imposiciones de roles sociales, los tabúes, así como también los poderes liberalizantes del deseo. ${ }^{6}$ El mundo agrario y sensual de Los papeles... no queda al margen del orden patriarcal: "Papá volaba en un carro, un avión hecho por él mismo, durante pocos días; le veíamos pasar entre dos alas largas y angostas, rozando el techo, se reía, y al instante, ya de pie, entre nosotros, daba sus serias órdenes; parecía otro” (II: 103). No sólo el padre es signo del orden, sino también la madre. En una relación paradójica, pero no inusual en la poesía de mujeres, por ejemplo en la de la chilena Gabriela Mistral, o la de la norteamericana Sylvia Plath, al profundo amor por la madre, de quien es una extensión, y al deseo de la hablante por agradarla se mezcla la impotencia hacia esa madre que impone límites y reglas. "Mi madre rezonga como una hoguera” (I: 278). "Se deshizo mi trenza; nuevamente, salí sin vestido; por esto mamá me persigue y me condena” (I: 285). “Al entrar dije:-Mamá, no me persigas, no me sigas. Déjame vivir, jugar, ata aquí tus figuras-. Pero ella acomoda huevos y manzanas, ubica vestidos./.../Y reaparece otra vez por todas partes” (I: 293). La hablante que se auto-identifica como Marosa en varios de los poemas se sabe limitada desde su nacimiento por el romance familiar:

Mi padre y mi madre me cercaban. Si iba hacia el norte estaba mi padre; si iba hacia el sur, también, estaba.

Si iba hacia el este, estaba mamá; y en el oeste, también estaba.

$\mathrm{Y}$ ambos estaban en las cuatro partes.

\footnotetext{
6 “...me puse el disfraz de lobo, el disfraz de león, los lentes de mariposa, me pinté las uñas y la boca./ /La presa iba por todo el prado. Bien se veía que era un niño de muy breve edad, blanco como nieve y algodón.../Y la presa, ya, era presa. La hinqué en las uñas. Y la engullo. Aún tiene un pequeño gusto a dulce huevo" (I: 303-04).
} 
Creo que era sonámbula y en sueños me escapaba, me iba desnuda; pero, al volverme, aún en el sueño, venía mamá y me daba miedo, me daba vergüenza.

... Me parece que, hoy, es el día de mi nacimiento. Papá y mamá dicen: "Se llamará Marosa” (I: 309)

El orden que se opone al vuelo, a la libertad, impone máscaras, representaciones para el “yo” que surge en los poemas y que nació “extraña”, con una naturaleza que la margina del orden social: "Toda la Creación estaba allí, esperando con ansiedad a aquel ser nuevo que venía. Y yo me despegué desde lo más hondo de mi madre, me erguí con el cabello rojo que se iba por el suelo, y mi extraña identidad” (I: 315). La "extraña identidad” no le permite asumir el papel de "mujer", con sus rituales sociales establecidos de noviazgo, matrimonio, hijos. Con un acervo de poetas mujeres que para crearse una voz tuvieron que cercenar parte de su identidad, la Marosa que se pregunta: “¿Por qué no puedo ser una mujer y sí un hada?” parece sintetizar cientos de años de interrogantes de mujeres poetas, aunque invirtiendo la naturaleza de la demanda. Ya no es la casa, ni los roles estereotipados de las mujeres los que le impiden a Di Giorgio asumir la escritura poética como poder liberador. Por lo contrario, es el poder de la escritura el que le impide saltar la frontera de la imaginación/realidad, y así queda atrapada en el plano de la imaginación: "no tengo casa; me destinaron el arco iris; pero estoy harta de esa lista fresa y de esa otra verde" (I: 315). La Marosa que se despega de la madre o surge de huevos coloridos como en los mitos, para transformar todo lo que asalta su mirada en poesía, no cuestiona el poder de su pluma. Sin embargo, al no tener "casa" carece del poder de ocupar un lugar en la sociedad. Si en el siglo xix, la pionera Emily Dickinson, a quien Di Giorgio considera "un alma gemela", denunciaba su condición desprivilegiada de "poetisa," declarándose "Nadie”, Di Giorgio, por el poder de la poesía, queda “prendida” “a nada” (I:274), a ser "una monje”, estar "casada con [ella] misma” (I: 315), como esos seres extraños de anillos verdes-rosa, o como el caracol.7 El universo poético de Los papeles ... no es prístino, ni ingenuo, ni anterior a la historia, aunque sí “salvaje” en su acercamiento al mundo de las cosas por las cuales habla.

En El pensamiento salvaje, Lévi-Strauss explica que hay dos modos diferentes de conocimiento científico o sea "dos niveles estratégicos en que la naturaleza se deja atacar por el conocimiento", siendo "el salvaje" "el más ajustado al de la percepción y la imaginación” (33). Semejante al "pensamiento salvaje,” la estrategia poética de Di Giorgio está movida por una "intuición sensible”. La percepción e imaginación de Di Giorgio la llevan a querer entender el mundo desde los elementos que lo constituyen, los

\footnotetext{
${ }^{7}$ Naturalmente y de manera similar a Emily Dickinson la falta de poder se vuelve virtud. Para Dickinson, Nadie es superior a Alguien, quien se vanagloria en un discurso pomposo y vacío para satisfacer a un público de tontos. Alicia S. Ostriker observa que el poema de Dickinson se basa en la duplicidad, ya que significa tanto lo que dice como su contrario. Y explica: "I use the term duplicitous rather than ironic because in irony the unstated meaning cancels the stated one, here, contrary meanings coexist with equal force within the poet. Dickinson genuinely despises publicity and power, prefers the private and powerless life -and the reverse is equally true" (40-41). En el caso de Marosa Di Giorgio, el concepto de duplicidad ilumina asimismo su relación con la poesía. Gracias a ella es Alguien y no tiene Nada, más allá de la riqueza de su imaginación.
} 
que para ella son las imágenes de las chacras de su niñez. Su poesía le permite re-crear un mundo concreto y mítico. Como en la poesía del bricolage, Di Giorgio habla por medio de las cosas que constituyen su mundo agrario y mítico (Lévi-Strauss 42). Esta cercanía entre el "yo" enunciante y el mundo enunciado, que siempre culmina en la metamorfosis de la hablante, permiten reificar el mundo profano y el sagrado, o sea el mundo del trabajo, de la escuela, de las tareas y rituales sociales, y el de la transgresión, el de la exhuberancia de los deseos que se articulan por medio de una naturaleza animada. Así se plasma el erotismo de Di Giorgio.

Con resabios surrealistas, el erotismo de Di Giorgio es, compartiendo el dictum bretoniano, el gran centro de la investigación estética. En la naturaleza se encuentran las fuerzas anárquicas de la sexualidad que llevan a la muerte para afirmar la vida, en un proceso cíclico e infinito. Así en el último capítulo de Los papeles..., la sección dedicada a la muerte de la madre, "Diamelas a Clementina Médici”, Marosa se dirige a la madre/ Blodeuwed[d], diosa de la tierra en flor, a la madre/mariposa celeste, a la madre/búho, a la madre/cisne para recordarle la fuerza erótica/vital de la naturaleza:

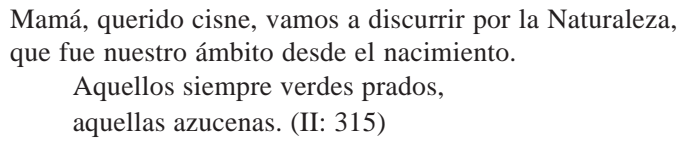

La fuerza erótica de la naturaleza posee la capacidad de explicar la muerte. En su trabajo canónico sobre el erotismo, Georges Bataille explica la vida como una inflamada agitación que está continuamente al borde de una explosión. Así: "beings given life whose explosive force is exhausted shall make room for fresh beings coming into the cycle with renewed vigor" (59). Esta verdad obvia y sobre la cual la humanidad ha reflexionado desde tiempos inmemoriales es la que mueve a los individuos, en su deseo ambiguo por la muerte, por el deseo de no ser eliminados en su proceso, hacia su torbellino. La muerte atrae por la calma de su atemporalidad, por la vida que sólo gracias a ella existe. Por otra parte, repugna por ser precisamente lo que marca la finitud humana, por ser las fuerzas de la aniquilación. Atracción y repulsión que se reproduce en el coito, como un acto canibalístico de comerse al otro, de volverse ese otro, después de la destrucción:

\footnotetext{
Desprendía una herminia de los árboles. ... Era carne deliciosa, misteriosa, de manzana con otra cosa; tenía por ahí espinitas y esto la emparentaba también a los pescados.

Luego, ella sacaba unos segundos, la lengua angosta, roja y movible, y se relamía, mirando si nadie la divisaba.

Volvía a las operaciones extrayendo otros armiñitos, desde las hojas infinitas, tupidas y vitales.

La pasión era tanta que sufría espasmos y alguna gota de sangre bajaba de su sexo. ... (II: 336).
}

Sin embargo, la muerte de la madre causa una crisis. Clementina, como diosa telúrica, era origen de la vida humana, vegetal, animal y mítica. Ella permitía la creación de una 
genealogía, la ubicación de la hablante en el mundo real e imaginario, y la interpretación y apropiación furtiva de su sistema de preceptos. ${ }^{8}$

Mamá, te llevo en brazos, estrella, nena del puerto del Salto, hija de Eugenio y Rosa, melliza de Josefa, hermana de Ida, esposa de Pedro, veo tus años junto al río, tu ir y venir al colegio (Preve), la Primera Comunión fija en la fotografía. La monja que te asistió. Y la boda.... (II: 304)

La desaparición de la madre que era guía del mundo natural, catalogadora de flores y animales, así como representante del sistema de reglas que aseguraba el equilibrio de "La Quinta,” y encendía el deseo de subvertir esas mismas reglas, quiebra el ciclo erótico de la vida. La persona poética queda des-ubicada, imposibilitada de desentrañar "la palabra críptica," "Mamá”:

Las dos sílabas iguales se cierran como dos valvas, ocultando una carne, un cuerpo inenarrable. Y el espíritu inserto en una perla.

Quiero analizar esa palabra críptica y no se puede. Giran en torno de mí las dos tapas de nácar, idénticas e inasibles: Ma-Má. (II:331)

Ese cuerpo “inenarrable” es el de la mujer que se dirige a la madre muerta. Ella es el espacio (el guion), el silencio que queda entre las dos sílabas iguales, "Ma-Má”, como enunciación primigenia de la niña que no deviene persona si las dos sílabas no se juntan, no la integran. La separación de las sílabas, como la apertura de las valvas que arrojan a la perla, expulsan a la persona poética al vacío.

Para Marosa, hija de Clementina ahora muerta, la fuerza explosiva de la gestación sólo se hace posible en un mundo fantasmagórico que toma forma en el poema. En ellos, la hija puede gestar las imágenes de la madre, las de todos los desaparecidos, así como la de "la transparente” e imaginaria “Quinta”. El “yo” poético deviene sujeto en su poder creador de fantasmas. El puje erótico que mueve hacia la muerte como la posibilidad de transformar al "yo" que escribe en fantasma y recuperar así casa, valva, y la palabra "Mamá”, también empuja a la circunvalación, al exceso y a la imposibilidad de poner punto final al poemario. El último poema de Papeles ... reafirma la continuidad del ciclo:

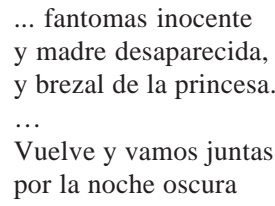

\footnotetext{
${ }^{8}$ Uso el término genealogía movida según el significado que le da Foucault. Para él: “...if interpretation is the violent or surreptitious appropriation of a system of rules, which in itself has no essential meaning, in order to impose a direction, to bend it to a new will, to force its participation in a different game, and to subject it to secondary rules, then the development of humanity is a series of interpretations. The role of genealogy is to record its history...” (151-52).
} 
por la luz del alba.

Dirán: Ahí va una hija con su madre

y una madre con su hija

hacia el nunca más. Hacia (II: 338)

El “yo” poético tendrá que seguir escribiendo, como la Scheherezade, o Sheherazade, de Las mil y una noches -hay que recordar que las historias inventadas cada noche por Scheherezade le aseguran la vida-no sólo para seguir existiendo, sino para mantener vivo un mundo mágico, necesario y extraño en la literatura uruguaya.

\section{LA ENTREVISTA}

La posibilidad de conocer, de hablar con la mujer que escribió y seguirá escribiendo Los papeles salvajes era excitante e inhibidora al mismo tiempo. La imagen de la mujerniña de largos cabellos rojos, que reiteradas veces se anuncia en los poemas, me recordaba incesantemente la descripción que hiciera Thomas Wentworth Higginson de Emily Dickinson, otra pelirroja, aparentemente tímida, en el momento de conocerla:

A step like a pattering child's in entry and in glided a little plain woman with two smooth hands of reddish hair ... in a very plain and exquisitely clean white pique and a blue net worsted shawl. She came to me with two-day lilies which she put in a sort of childlike way into my hand and said: "These are my introduction" in a soft frightened breathless childlike voice... (2: 473)

¿Cómo me recibiría Marosa? Sabía que Marosa Di Giorgio era una mujer retraída. Sabía igualmente, por lo que se desprendía de mis múltiples lecturas de su obra, que era una escritora poderosa y que había podido hacerse un lugar en el difícil sistema cultural uruguayo, especialmente para las mujeres. La oportunidad de entrevistarla alimentaba mi deseo y curiosidad de ver detrás de las máscaras.

Sin embargo, la entrevista no podía caer en los vicios que el poeta mexicano, José Emilio Pacheco, denuncia en su poema "Una defensa del anonimato":

Extraño mundo el nuestro: cada día

le interesan más los poetas;

la poesía cada vez menos.

El poeta dejó de ser la voz de su tribu, aquel que habla por quienes no hablan.

Se ha vuelto nada más otro entertainer.

Sus borracheras, sus fornicaciones, su historia

clínica,

sus alianzas o pleitos con los demás payasos del circo, o el trapecista o el domador de elefantes,

tienen asegurado el amplio público

a quien ya no hace falta leer poemas. (74) 
Por supuesto que tratándose de una mujer no podía existir la nostalgia de la poeta como voz de su tribu, ya que ellas nunca lo fueron. Tampoco, por ser una mujer, importa mucho la figura de la poeta. Paradójicamente, la misma interesaba más cuando se vivía el tiempo de la entrada en la modernización y las mujeres que tomaban la pluma eran “poetisas” (Molloy 115). Con respecto a la poeta como entertainer, con un sentido diferente al adjudicado por Pacheco, me fascinaba saber de ese arte tan antiguo del recitado y renovado en los últimos años en el performance, del cual Di Giorgio es representante.

Por otra parte, estaba el riesgo de transformarla durante la entrevista, y a pesar mío, en sujeto de estudio, en conejillo de Indias para probar teorías literarias feministas, mayoritariamente del norte, que habían iluminado mis lecturas de la poesía de mujeres. Otro poema, esta vez de una mujer rioplatense, la argentina Susana Thénon, me advertía, con su burla cargada de ironía, el problema:

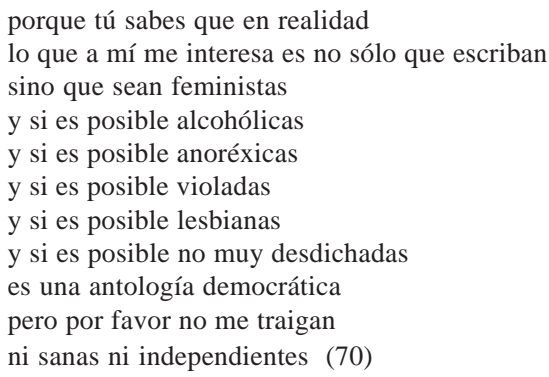

Para no caer en los errores señalados por el poeta mexicano y la poeta argentina, escribí preguntas que servirían de base para la entrevista, y la noche del 6 de julio de 2001 me reuní con Marosa Di Giorgio en su apartamento montevideano. Di Giorgio es una mujer "sana” "e "independiente”, aunque conviene hacer una aclaración. El término "sana" puede caer en el estereotipo de "normalidad" dictado por un momento y sociedad determinados, y la obra de Di Giorgio cuestiona y destruye constantemente las expectativas de "normalidad" de los lectores. Ciertamente, se trata de una mujer "saludable" e "independiente". A pesar de las coincidencias con Emily Dickinson, nunca habría podido ser descripta en los términos de Higginson. Desde la puerta de entrada se hacía presente ese mundo de figuras míticas, religiosas, mágicas. Cerca del timbre había diminutas calcamonías de santos. En el interior de su apartamento los retratos de su madre y tías dominaban la sala, así como una reproducción de la Mona Lisa. Todos los fantasmas la acompañaban y no estaba sola. El tiempo transcurrió sin sentirlo. Entrar en el habitat de Marosa Di Giorgio era penetrar en “el mar de Amelia”. Las preguntas se leyeron, pero Di Giorgio las contestó por escrito, más tarde, reafirmando sus máscaras literarias, y legitimizando la magia del mundo que ella minuciosamente ha ido creando.

La insistencia en lo literario me hizo pensar en Borges. El falseamiento y la magnificación literarias serían las únicas posibilidades de la existencia. En oposición al concepto de Borges de existir perdiéndose en la literatura, el verso dariano, "si hay una alma sincera, ésa es la mía” (27), se imponía en el caso de la uruguaya. La ficcionalización 
de la biografía de Marosa Di Giorgio por Marosa Di Giorgio es la muestra de su mayor sinceridad. Paradójicamente, no habría tanta diferencia con Borges, ya que también para ella, su "vida es una fuga y todo lo pierd[e] y todo es del olvido, o del otro" (Borges 808). Sin embargo, tratándose de una poeta mujer que comenzó a publicar en los cincuenta, no hay "una otra" anterior con gustos legitimados, una "Marosa y yo", ${ }^{9}$ sino las múltiples máscaras que le dan miradas que iluminan el mundo desde el más allá de lo preconcebido. Sin ellas sería "Nadie", con ellas está atada a la "Nada" social, pero libre en el reino de la imaginación que hace posible una realidad más rica y siempre misteriosa.

\section{Preguntas}

María Rosa Olivera-Williams: Imaginación y realidad aparecen íntimamente conectadas en tu obra. Se podría decir que realidad e imaginación se asientan en un mundo rural concreto y a la vez creado, entonces quisiera que me contaras de tu infancia en Salto y también de los relatos sobre Italia que debieron coadyuvar al vuelo de tu imaginación de niña.

Marosa Di Giorgio: Todo lo que cuento y canto es mi infancia en una zona agraria, oscura, oclusa y a la vez libérrima e irisada, donde transcurrieron mis primeros pasos. Vi la Creación, Maravilla, el altar de Dios, poblado de liebres, azucenas, de dientes y corolas. Todo estaba allí, todo estará por siempre allí.

Los recuerdos italianos de padre y abuelo se imbricaban perfectamente también allí. Soñé con lobos blancos más altos que la casa, soñé con nieve, que era suave y leve como pétalo de gladiolo; también era un ensueño la luna enorme de aquellos campos, en medio del aire de plata y de cristal. Estrellas y luciérnagas ardiendo por doquier, sin discernirse unas de otras.

MROW: ¿Cómo te relacionas y relacionabas con la naturaleza, los animales?

MDG: Todos los vegetales y animales me dieron su encanto y vienen resucitados, siempre vivos, a los poemas, los eróticos cuentos, en que hacen de novios, de donceles.

MROW: ¿Cómo se mantiene viva esa imaginación primigenia que confunde fundiendo mundo humano con el animal, vegetal, mítico, en la ciudad y en la etapa adulta?

MDG: Cómo, no sé. Pero es mi columna, mi fontana, mi luz de gloria.

MROW: Marosa es una poeta solitaria. Me refiero a soledad en el sentido de creadora de una obra única, difícil de catalogar, así como de voz poética que se crea desde la soledad. Entonces, ¿̇la soledad sería un prerrequisito en tu caso para la creación?

MDG: Sí. Es lo que venía diciendo. Y en la soledad soy una reina de pie desnudo, saya campesina, un ramo de margaritas en la mano.

MROW: Si bien, como te acabo de comentar, tu poética rechaza encasillamientos clasificatorios, se podría decir que la misma es esencialmente erótica, ¿verdad?

MDG: Y... el erotismo se presenta. Más bien, está. Todo lo que existe está erotizado, tiene un relámpago visible, o no, permanente. Un "rayo que no cesa”. Con ese relámpago, ese rayo, tramé Los papeles salvajes, los Misales, el Camino de pedrederías, la Reina Amelia, y tramaré lo que vendrá.

\footnotetext{
${ }^{9}$ Es tentador detenerse en la diferencia entre el uso del apellido en Borges y el nombre de pila, "Marosa", en las obras de ambos "transplatinos". Sin embargo, queda para otro momento.
} 
MROW: ¿Cuándo comenzaste a escribir?

MDG: Desde siempre sentí la necesidad de escribir, desde que nací. Cuando iba a la escuela custodiada por roseros en fila con las rosas rojas, doradas, lilas (algunas de las cuales, Clemen, mi madre, elegía cautamente), y las clavelinas, y el miosotis con ojo azul. Así nació y creció la poeta Marosa. Marosa, la mantis religiosa, que tabletea su mensaje.

MROW: En una etapa del desarrollo cultural (después de las vanguardias) en el que las palabras “originalidad” y “original” han perdido su poder, de todas maneras, en tu caso, cabe hablar de "unicidad”..., entonces quisiera saber si has encontrado "almas gemelas" o "primas distantes” en la literatura.

MDG: Ando sola. Pero voy a nombrar sólo cinco almas, que me miran y miro. Hay otras Emily Dickinson, Emily Brontë, Edna Saint Vincent Millay, Silvia Plath, Concepción Silva Belinzon. La uruguaya Concepción Silva Belinzon. Las nombro porque son almas ya desaparecidas.

MROW: ¿Has sido o eres lectora de la Biblia?

MDG: Sí. Hay gigantes poemas dentro de ese tremendo libro.

MROW: En los ecos de otras obras literarias que tu poesía recrea, me parece sentir resonar ecos románticos. ¿ Te sientes vinculada al romanticismo, especialmente a algunas muestras del romanticismo ruso?

MDG: Tal vez esa nostalgia, esa leve lluvia sobre los seres y las cosas. Tal vez estoy sentada en la sala mirando un eterno álbum. Pero hay un diablo, rojo como un ají, un icono erotizado, que me enhebran y dirigen.

MROW: ¿Qué piensas de los géneros literarios? ¿Tus cuentos y novelas podrían ser nuevos capítulos de Papeles salvajes?

MDG: Pienso, siento que [mi obra] es un trabajo en bloque; una sostenida atmósfera. Todos son papeles salvajes, todas son misas; por allá y acá va un camino de pedrerías. La reina Amelia, Amelia la reina, se levanta en cualquier sitio.

MROW: Me gustaría que me hablaras, especialmente porque no te he visto, de tus performances. ¿Te continúas por medio de ellas en el mundo mágico de tus creaciones?

MDG: Se trata de un rito, un ritual, un reescribir diciendo. Es como haber encontrado vino de ocultas misas y beberlo en vaso de piedras rojas, delante del prójimo. Miren qué bebo. Es hablar con un clavel.

MROW: ¿Qué momentos consideras los más importantes de tu vida?

MDG: No sé qué señalar. Cada momento es muy importante. El alma trabaja siempre. No sé cómo. Es un trabajo inexplicable, un trabajo de alma.

MROW: ¿Cómo ves el curso de tu obra desde Poemas (1954) hasta Reina Amelia (1999) o Diamelas a Clementina Médici (2000)?

MDG: Me olvido del tiempo, pero me despliego en él. El tiempo, ese ser rico y angustioso.

MROW: ¿Cuál es tu libro más querido?

MDG: Es siempre el mismo libro. Escribo sólo un libro con muchas porciones. Acaso, La liebre de marzo.

MROW: ¿Cómo crea Marosa al personaje/poeta Marosa Di Giorgio?

MDG: No me propongo nada. Uso vestimenta muy sencilla, cabello largo, uñas rojas, y ahora conseguí unos aros o caravanas, en forma de rosas. Nada más. 
MROW: ¿Cuáles son tus hábitos de escribir, de trabajo?

MDG: Sin hábitos, al azar. Cuando la cosa en mi interior empieza a suceder, aparecen la hoja y el lápiz.

MROW: Las mujeres poetas se han quejado desde siempre de estar marginadas, ignoradas, silenciadas por la hegemonía poética masculina, proyección de un mundo de cultura patriarcal. Para ejemplos, citemos a dos de "tus almas gemelas": Emily Dickinson, quien se autodefine como "nadie”, “I’m Nobody”, y Sylvia Plath, quien muestra la dificultad de una autodefinición autónoma, en su deseo de desaparecer en el poema, “And I have no face, I have wanted to efface myself”. ¿Qué pasa con Marosa? ¿Necesita del diálogo con otros?

MDG: Soy callada, de apariencia tímida, distraída, creo. Pero, también, de tanto en tanto, me gusta charlar, vaso de negro vino, o negro café, por medio.

MROW: ¿Cuáles son los temores de Marosa?

MDG: Todos sentimos un cierto miedo siempre. Como si esa noche fuera a ingresar el vampiro. ¿Cuál? El que está oculto y alerta en el follaje desde siempre.

MROW: ¿Estás trabajando en una nueva obra?

MDG: Estoy esbozando otras diabluras o diableces erótico-místicas. En fin.

MROW: ¿Cómo ves el mundo cultural uruguayo en este momento?

MDG: Uruguay es, en su sencillez, un hermoso país. Pero hay como un manto, una cosa gris, que ninguna tijera puede rasgar.

IV. PoEmas

Verdes, color rosa, anilladas, dibujadas. Se dice de ellas que tienen relaciones consigo, y se las ve en el espasmo.

O rígidas como un dedo alcanzan a beber en la fuente de las rosas. Están emparentadas con las rosas, las romelias y el peral. Las consideran sólo ensueños, representación de los pecados de los hombres. son, de verdad.

Pero, yo, de niñita, a la luz del sol y de la luna, creo en ellas, sé que

Las vi abrir los labios, negros como la noche, la dentadura de oro, en pos de una almendra, una pepita de calabaza;

enfrentar la propia línea, jugando y peleando; y en el amor a solas, retorcerse hasta morir.

Bajó una mariposa a un lugar oscuro; al parecer, de hermosos colores; no se distinguía bien. La niña más chica creyó que era una muñeca rarísima y la pidió; los otros niños dijeron: -Bajo las alas hay un hombre. Yo dije: -Sí, su cuerpo parece un hombrecito.

Pero ellos aclararon que era un hombre de tamaño natural.

Me arrodillé y vi. Era verdad lo que decían los niños. ¿Cómo cabía un hombre de tamaño normal bajo las alitas?

Llamamos a un vecino. Trajo una pinza. Sacó las alas. Y un hombre alto se irguió y se marchó. 
Y esto que parece casi increíble, luego, fue pintado prodigiosamente

en una caja.

Siempre había uno de nosotros arriba de un árbol. Y eso parecía lo más natural. Los que estábamos abajo conversábamos de cualquier cosa con los que estábamos arriba.

Allí va mamá trepándose entre las peras como un gato.

Y una de las primas come entre las ramas una poma; y está sin cendales; se le ve desde abajo el sexo como las guindas en esa tarde verde luz.

Yo trepo a un árbol y trepo a otro, a otro, hay segundos en que estoy volando.

-Mira cómo va ....!

-Mira cómo se va yendo....!

Ya estoy en la chacra de los vecinos.

Yo disimulo allá arriba; soy cauta; pero ellos ven todo desde las ventanas. Yo ya dejé esa chacra, y otra, otra, viajo por los árboles remotísimos.

Entonces me da un terrible miedo. De no poder volver. Mas, encuentro en

segundo la clave y retrocedo.

Vuelvo árbol por árbol y salteo algunos, hasta caer en mi patio, desde donde repaso la hazaña en las arboledas, y por ende, mi oscuro porvenir.

(II: 333)

\section{BiBLiografíA}

Bataille, Georges. Erotism: Death \& Sensuality. Mary Dalwood, trad. San Francisco: City Lights Books, 1986.

Borges, Jorge Luis. Obras completas. Buenos Aires: Emecé, 1974.

Darío, Rubén. Cantos de vida y esperanza. Madrid: Espasa-Calpe, 1971.

Di Giorgio, Marosa. Los papeles salvajes. 2 vols. Buenos Aires: Adriana Hidalgo, 2000. Rosa mística. Buenos Aires: Interzona, 2003.

Reina Amelia. Buenos Aires: Adriana Hidalgo, 1999.

Camino de las pedrerías. Montevideo: Planeta, 1997.

Misales. Montevideo: Calicanto, 1993.

Echevarren, Roberto. Transplatinos. Muestra de poesía rioplatense. México: El Tucán de Virginia, 1991.

Foucault, Michel. “Nietzsche, Genealogy, History”. Language, Counter-Memory, Practice: Selected Essays and Interviews. Donald F. Bouchard, ed. D. F. Bouchard y Sherry Simon, trads. Ithaca: Cornell University Press, 1977.

Higginson, Thomas Wentworth. Emily Dickinson. 3 vols. T. H. Johnson, ed. Cambridge: Harvard University Press, 1971.

Jacubus, Mary. Reading Women: Essays in Feminist Criticism. New York: Columbia University Press, 1986.

Kirkpatrick, Gwen. The Disonant Legacy of Modernismo: Lugones, Herrera y Reissig, and the Voices of Modern Spanish-American Poetry. Berkeley: University of California Press, 1989. 
Lévi-Strauss, Claude. El pensamiento salvaje. Francisco González Arámburo, trad. México: FCE, 1990.

Mattoni, Silvio. “Allá donde alumbra la imagen”. Prólogo. Di Giorgio. Los papeles salvajes I: 5-10.

Miller, Nancy K. "Rereading as a Woman: The Body in Practice”. The Female Body in Western Society. Susan Ruben Suleiman, ed. Cambridge: Harvard University Press, 1986.

Molloy, Sylvia. "Female Textual Identities: The Strategies of Self-Figuration”. Women's Writing in Latin America. Sara Castro-Klarén, Sylvia Molloy and Beatriz Sarlo, eds. Boulder: Westview Press, 1991.

Ostriker, Alicia Suskin. Stealing the Language. The Emergence of Women's Poetry in America. Boston: Beacon Press, 1986.

Pacheco, José Emilio. Los trabajos del mar. México: Era, 1983.

Penco, Wilfredo. “Entrevista a Marosa Di Giorgio.” El País Cultural (Montevideo, 10 de abril de 1990).

Porzecanski, Teresa. “Marosa Di Giorgio: Uruguay’s Sacred Poet of the Garden”. A Dream of Light and Shadow. Marjorie Agosin, ed. Albuquerque: University of New Mexico Press, 1995.

Rama, Ángel. La generación crítica 1936-1969. Montevideo: Arca, 1972.

Thénon, Susana. Ova completa. Buenos Aires: Sudamericana, 1987. 